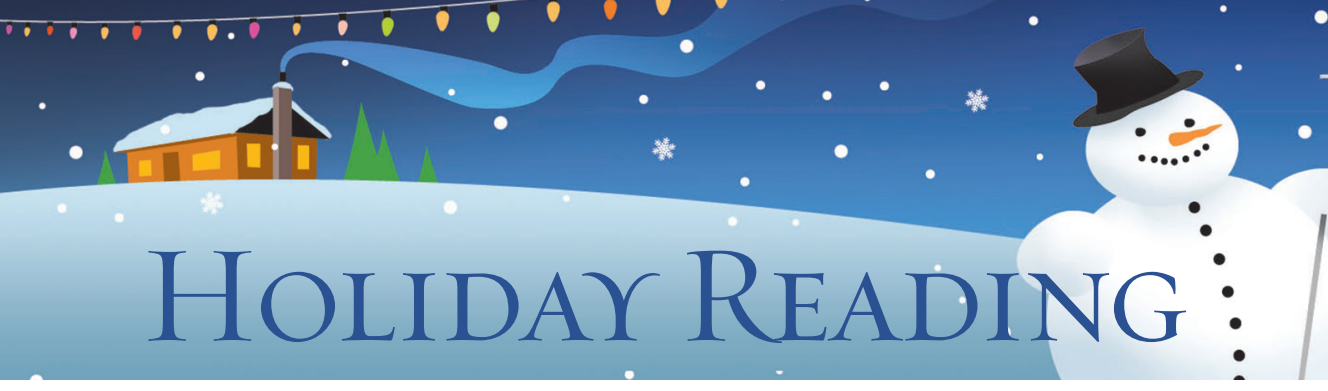

\title{
Diving into the ice bucket challenge
}

\author{
Anil Adisesh MB ChB MD, Sarah Melville BSc CRA, Thomas Pulinilkunnil PhD, Sohrab Lutchmedial MD, \\ Keith R. Brunt PhD
}

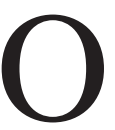

ver the past year, amyotrophic lateral sclerosis (ALS) associations have benefitted from people embracing the "ice bucket challenge," in which cold water is tipped over the participant's head. To date, about 150 million dollars has been donated worldwide as a result of the challenge. However, concerns have been raised as to the safety of this endeavour. We surmised that head and facial contact with cold water may induce a diving response: reduced heart rate, peripheral vasoconstriction and apnea.

\section{Stuff we did}

Two investigators (A.A. and T.P.) participated in the ice bucket challenge. Their pulse and blood pressure responses were monitored using an oscillometric wrist cuff sphygmomanometer (Biosign Pulsewave/Cloud DX). Measurements were made at baseline, and during and after the challenge (in which $16.5 \mathrm{~L}$ of water at $3^{\circ} \mathrm{C}$ was poured onto each participant's head from behind on verbal command of the photographer) (Figures 1 and 2). After the challenge, appropriate donations were made to the ALS Association, and suitable nominations were issued for subsequent challenges.

\section{Important things we found}

Participant 1 (A.A.) showed apnea during the pouring of the water, an initial deep inspiration after the pouring stopped, and slow, deep inspirations for about 10 seconds thereafter. The participant's systolic blood pressure rose by $18 \mathrm{~mm} \mathrm{Hg}$ during the challenge, returning to prechallenge levels at 3 minutes; arterial pressure increased $22 \mathrm{~mm} \mathrm{Hg}$ during the challenge. The participant's pulse slowed during the challenge, but briskly increased on cessation of the challenge, showing 10\% variability (Figure 1).

Participant 2 (T.P.) showed the same respiratory pattern as his compatriot, although the water was poured more slowly by the participant's research student, who was enjoying the moment. The participant's initial breath occurred at the end of the pour. The participant's systolic blood pressure rose by $29 \mathrm{~mm} \mathrm{Hg}$ during the challenge and returned to prechallenge levels at 3 minutes; arterial pressure increased $29 \mathrm{~mm} \mathrm{Hg}$ during the challenge. The participant's pulse, however, increased during the pouring phase, showing 18\% variability (Figure 2).

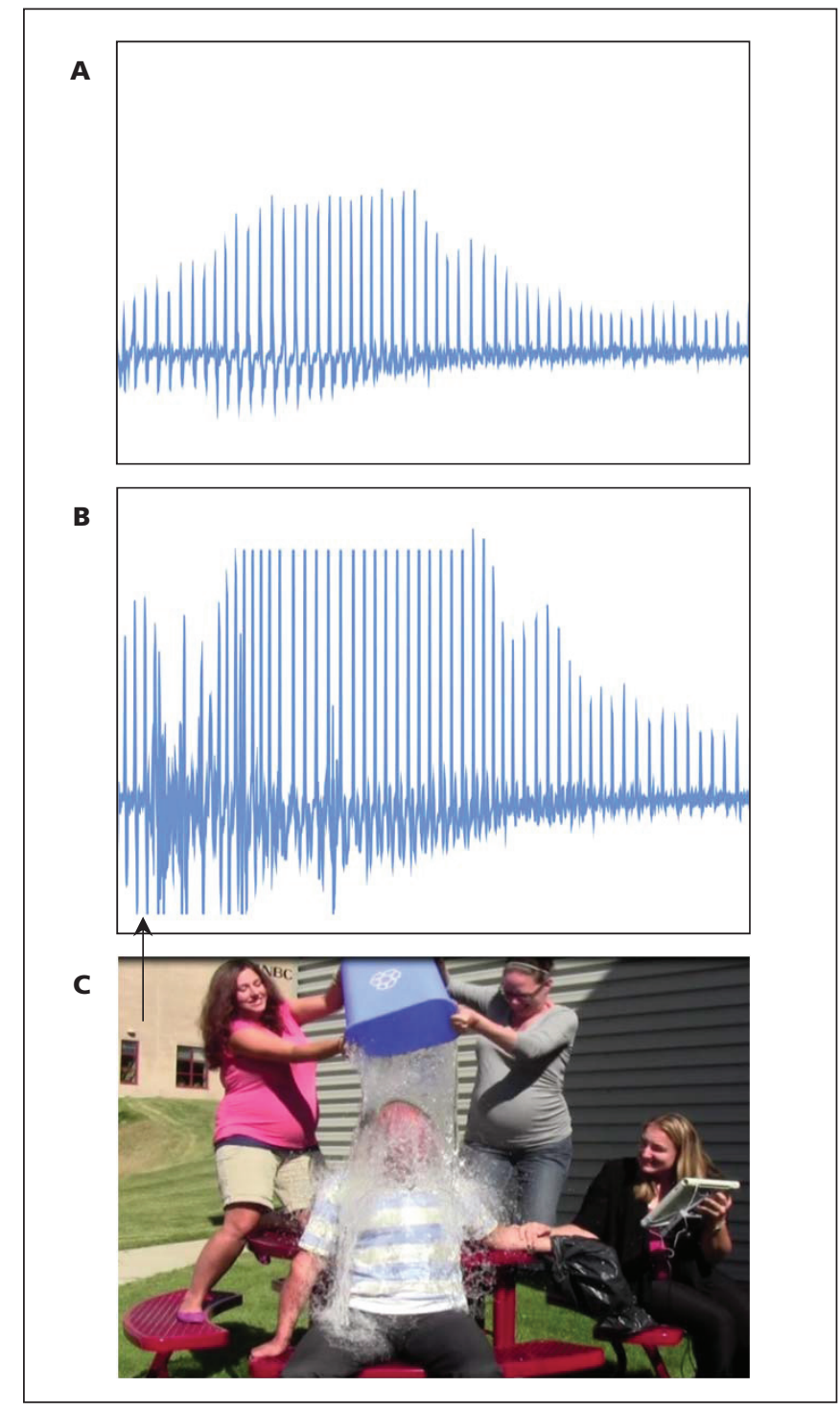

Figure 1: Blood pressure recordings at baseline $(A)$ and during the "ice bucket challenge" (B) in participant 1. Baseline systolic pressure was $155 \pm 20 \mathrm{~mm} \mathrm{Hg}$, arterial pressure was $45 \mathrm{~mm} \mathrm{Hg}$ and heart rate variability was $\mathbf{5 \%}$. In-challenge systolic pressure was $173 \pm 12 \mathrm{~mm} \mathrm{Hg}$, arterial pressure was $67 \mathrm{~mm} \mathrm{Hg}$, and heart rate variability was $10 \%$. Time at which the accompanying photograph (C) was taken is indicated with an arrow. 


\section{Chit chat}

Participant 1 felt physiologic changes consistent with the diving response. The reaction of participant 2 differed, in that his pulse increased, rather than decreased, during the challenge. We suggest a more complex response is involved in the ice bucket challenge, consisting of components related to both the diving response and the cold shock reflex. The latter causes an initial respiratory gasp, followed by hyperventilation, increased pulse and increased cardiac output.

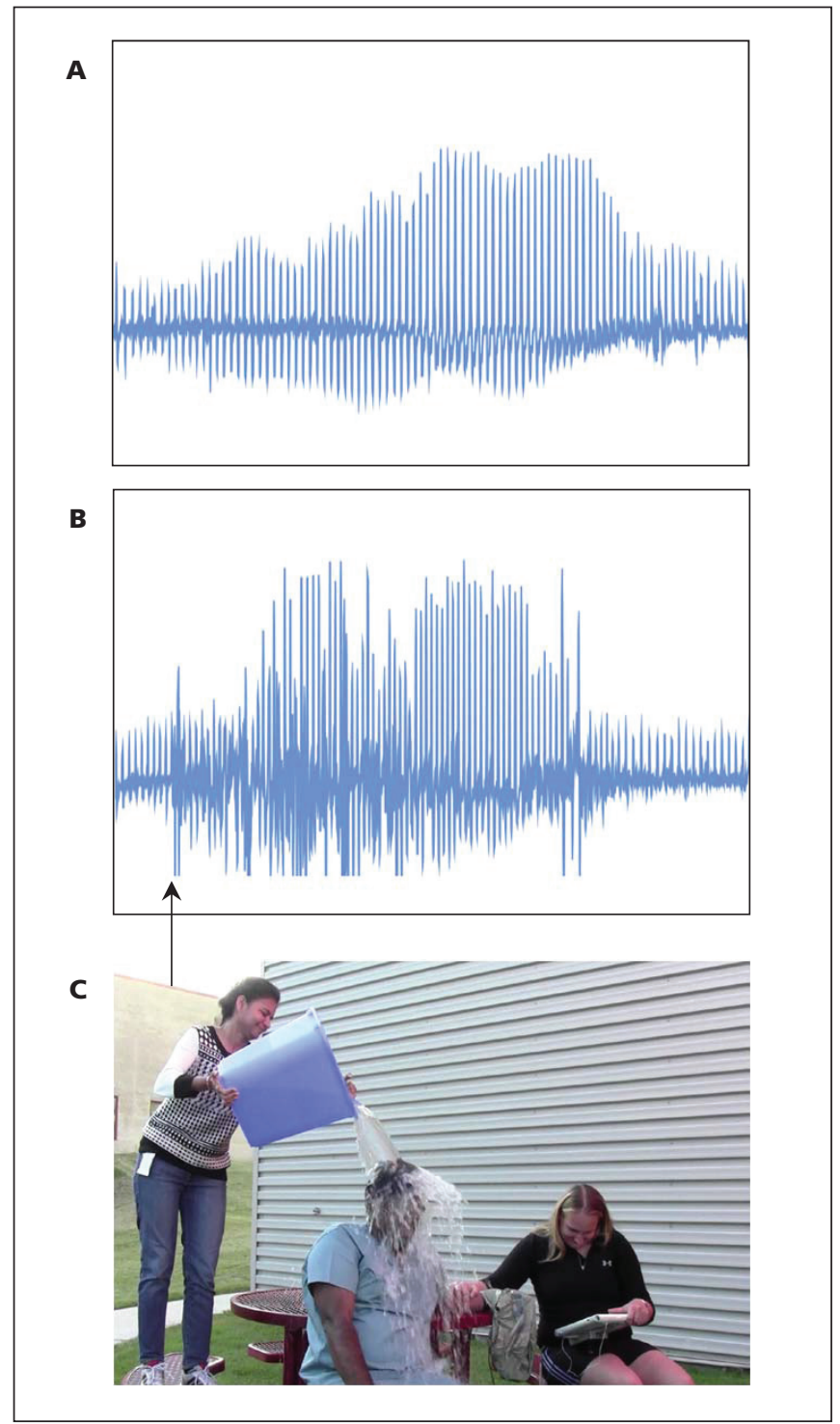

Figure 2: Blood pressure recordings at baseline (A) and during the "ice bucket challenge" (B) in participant 2. Baseline systolic pressure was $144 \pm 16 \mathrm{~mm} \mathrm{Hg}$, arterial pressure was $48 \mathrm{~mm} \mathrm{Hg}$, and heart rate variability was $4 \%$. In-challenge systolic pressure was $173 \pm 33 \mathrm{~mm} \mathrm{Hg}$, arterial pressure was $77 \mathrm{~mm} \mathrm{Hg}$, and heart rate variability was $18 \%$. Time at which the accompanying photograph (C) was taken is indicated with an arrow.

\section{Reasons not to believe what we say}

We were limited to observations involving only 2 participants (principal investigators), because volunteer recruitment would have required research ethics board approval. Participant 2 wore spectacles, which may have interfered with the diving reflex; however, this seems unlikely in view of the thorough dousing he received. We did, briefly, consider repetition to check the repeatability of our results, but we quickly dismissed that idea.

\section{Random thoughts}

A similar effect can be obtained from a cold shower; we had thought a considerable body of Scandinavian literature on the topic might exist, but none was found. We would therefore encourage further ice bucket challenge experimentation to elucidate the, in our opinion, not unpleasant phenomenon.

Correspondence to: Anil Adisesh, anil.adisesh@dal.ca

Competing interests: Sohrab Lutchmedial and Keith Brunt report grants from Biosign Technologies Inc., Cloud DX Inc., Health + Life Science New Brunswick and the New Brunswick Health Research Foundation during the conduct of the study. No other competing interests were declared.

Affiliations: Dalhousie Medicine New Brunswick (Adisesh, Melville, Pulinilkunnil, Brunt), Saint John, New Brunswick; Saint John Regional Hospital (Lutchmedial), Saint John, New Brunswick.

Contributors: Anil Adisesh was nominated for the "ice bucket challenge" and wanted his participation to leave a legacy for the scientific community; he conceived of this idea. He was also responsible for the data analysis and writing the original draft of the paper. Sarah Melville is the master operator of the instrumentation and was responsible for the acquisition of data and protecting the device from water damage; she succeeded: no devices were harmed in the execution of this study. She also edited the drafts for correct terminology of the oscillometric wrist cuff device and was responsible for the data analysis output from the device and artwork for submission and publication. Thomas Pulinilkunnil was nominated to participate in the ice bucket challenge by Anil Adisesh. Being a cardiovascular researcher, he wanted the reassurance of some cardiac monitoring and was key to the collection of additional data. He reviewed and approved the report, and graciously gave consent for the publication of his photos. Sohrab Lutchmedial is an expert interventional cardiologist who offered his professional advice and support for the study. He gave his approval for the use of the device for this study, as well as his approval of the original and final drafts for submission and publication. He is keen for the follow-up phase of the study this winter to investigate the hemodynamic effects of jumping from a hot tub into a heap of snow. Keith R. Brunt gave his approval for the use of the device for the execution of the study. Although he refrained from getting wet because of his fear of cold water, he did make two generous monetary donations to the ALS Association. He edited all drafts and created the original idea for the layout of the figures. Honourable mention goes to his judicious selection of the photos from the video of his colleagues with respectful good humour.

Acknowledgments: The authors thank Erinor Jacob for photography; Purvi Trivedi, JoAnne Burke and Nikki Wellwood for their enthusiastic support in the execution of the stimulus used in this study; and the research support of the New Brunswick Health Research Foundation, and Health + Life Science New Brunswick. The principal investigators thank each other and convey their mutual respect for getting iced and cutting cheques during the execution of this study. The authors acknowledge the continuing need for support of the ALS Association's mission.

CMAJ 2014. DOI:10.1503/cmaj.141241 